\title{
43 SOURCE NETWORKS FOR FORMATION OF VIRTUAL ENTERPRISES ACTIVE IN ELECTRONIC SYSTEMS DESIGN
}

\author{
Maciej Witczynski \\ Silesian University of Technology, Gliwice, Poland, witczynski@ciel.pl.
}

POLAND

\begin{abstract}
The paper proposes a model of a source network that can be applied for organizations active in different fields and especially in electronic systems design. In the second part of the article some implementation details are given concerning an IT system module to deal with dynamic virtual enterprise initiation. Search and selection of partners needed for collaborative design is performed with the use of web services technology. At the end we envisage a possible scenario of Virtual Enterprise creation for electronic design. Proposed model and methodology jointly with the applied technology make this procedure fast, simple and semi-automatic, thus very appropriate for an electronic design domain.
\end{abstract}

\section{INTRODUCTION}

The second half of 20th century was a time of fast growth of electronics. In the late 60-s Gordon E. Moore, one of the founders of Intel Company, predicted that the complexity of silicon integrated circuits (IC) would be regularly doubling about every 18 months. His predictions have been valid till nowadays and the trend still continues. Complexity of the IC can be measured by the number of single transistors located in a chip. Systems being developed within the last decade, like for instance: Field Programmable Gate Arrays (FPGA) and Application Specific Integrated Circuits (ASIC) include hundreds of millions of transistors. So complex systems are called Systems-on-Chip (SoC) as they incorporate on their one silicon structure the whole system including one or more microprocessors, large memory, analogue modules, input/output interfaces, connection buses, and peripheral elements.

Producers of electronic equipment are under a constant pressure to shorten the time between conceptualization of a new product and the time the product enters the market. In addition, producers aim at customization of the product in order to match requirements of a particular customer (or a group of customers) and bundle with it a set of additional services that span over the product lifecycle. These trends force electronic companies to seek for new design methods that improve design efficiency. On one hand a partial remedy can be a use of new types of hardware description languages, on the other one, a new "IP re-use design" paradigm can constitute a solution. Design re-use is based on previously designed electronic components, called Intellectual Property (IP) components that are used as pre-designed blocks of a newly designed system. This type of design can be especially fruitful when employed in collaborative environments of several 
electronic companies that are IP component owners. Here comes the idea of a source network of electronic companies that can share among each other their IP components (Witczyński, 2005). Besides, members of the source network can share other resources, like design tools, competencies, etc. Creation of a dynamic virtual enterprise (VE) in response to market demands can additionally influence time-tomarket decrease. Thus, collaborative electronic design performed by VE created within the source network can be the remedy to increasing requirements but it will work only when all cooperative processes both during a VE action but also during a source network operation are conducted in an agile and efficient way.

The rest of this paper is structured as follows. Section 2 shortly presents overviews of published relevant research results with stress on model and technology aspects. Section 3 describes basic models proposed for the source network. Section 4 addresses some issues related to the technology implemented in a context of a VE initiation module of an IT system. Section 5 depicts a scenario example of an electronic design initiation. Section 6 concludes the work and points out the innovations in the author's approach.

\section{EXISTING SOLUTIONS}

Many $R \& D$ projects addressed already the issue of computer supported source networks. Research based on a cluster of Virtual Organization (VO) related projects (Katzy, 2005) summarized VO modeling approaches. According to these studies a list of basic management roles in VO has been recognized. It includes: competence manager, project manager, auditor, network-coach, manager of in-/outsourcing, and broker. Prime actors in source networks named also Virtual Breeding Environments (VBE) have been identified in (ECOLEAD, 2005) as well.

These are:

- VBE Member - an organization registered at the VBE and ready to participate in the VBE activities

- VBE Administrator - an organization responsible for the VBE operation, evolution, and promotion

- Opportunity Broker - an organization that acquires new collaboration opportunities by marketing VBE competencies and negotiating with customers

- VO Planner (Integrator) - a player that identifies the necessary competencies and capacities, selects proper partners, and structures the new VO when a collaboration opportunity appears (often Broker and VO Planer can be the same organization)

- VO Coordinator - an organization that coordinates a VO during its life cycle

- Common model/information/tool Provider

- VBE Advisor

- Public Guest.

Proposed IT solutions in $R \& D$ projects were based on various technological approaches (Camarinha Matos, 2005). A computer assisted approach was proposed in the Prodnet project. VO creation and coordination functionalities were implemented in Borland C++ on the PRODNET platform (Camarinha Matos, 1997, 2001). The PRODNET platform included two main modules for each node- 
enterprise in the network: Internal Module and Cooperation Layer. The Internal Module included the complete structure of a specific company's information (data bases, information systems, etc.). The Cooperation Layer comprised coordination functionalities containing negotiation support system for facilitating partners search and the contractual processes during the formation of a $\mathrm{VE}$, management of a contracts data base, and electronic catalogues (Camarinha Matos, 1997).

Agent based approaches were employed by different groups with various architectures. An example of such a solution is the VE Cockpit system described in (Rabelo, 2004), where multi agents were implemented with use of $\mathrm{C}++$, Java, $\mathrm{XML} / \mathrm{Corba}$. The system was composed of local relational databases and a number of agents realizing system functionalities through three main tools (i.e. VE Configuration tool, VE Design tool, and VE Integration tool). The tools supported with different levels of automation following VE creation phases: the specification of the type of information exchanged among VE partners, the integration of VE partners' legacy systems with VE platform, the identification of VE topology, establishing access rights for VE partners.

A service based approach considers companies that are potential members of VE as "service providers". Collaboration among companies is based on sharing the services by the companies. There is one entity that keeps a catalog of services announced by various VE members. Three main functions are executed by the network members: service publishing, discovering and invoking. Web services (WS) are a proper technology for this approach. There is however no direct partners search in this case. Searched and selected are services offered by different VE members and then they are composed in more complex tasks (Camarinha Matos, 2005, dos Santos, 2004).

Another solution from the technology point of view is a mix of the two later mentioned. It includes both technologies: computer agents and web services. A proposed solution of this type is XESS (XML based Expert System Shell). The system contains three main components: the Business Rules Composer, the Agent Administrator, and the Business Rules Engine Agent. All these components together give the possibility to integrate data and plan common business processes in VE with a special attention to a virtual multi-organizational supply chain (Shields, 2004; Camarinha Matos, 2005).

\section{INFRASTRUCTURE MODEL}

This paper concentrates on the concept of a source network incorporating companies active in electronic systems design and its efficient operation. In this section its base model is depicted. By the base model we mean a management model that describes the structure of the network, main roles, and its functionalities. The source network is a group of companies that joined their forces and developed a common preparedness to quickly respond to specific market needs and customer demands. All companies in the network can play certain role according to the network architecture and specific situation at the moment. In the case of electronic design source network we can see four main characters of member companies. These are: Network Manager (NMG) - preferably one company for the whole network, Network Broker (NB) - one or few companies in the network, Project Manager 
(PM) - potentially all members, in a particular moment the company that won the competition for the project coordination, Network Member (NMB) - all companies in the network - see Figure 1. The architecture and main roles are similar to those applied in the research cited above. Hence, our proposal can be also adopted in other disciplines. The difference is that we limited the number of key roles to only four in our solution. This results in a simplification of the source network model and consequently in a plain IT infrastructure. This could be achieved by fastening together VO Planner and VO Coordinator as one Project Manager. It is quite natural, especially in electronic design sector. Roles like Opportunity Broker and VO Planner should be kept separate in our opinion.

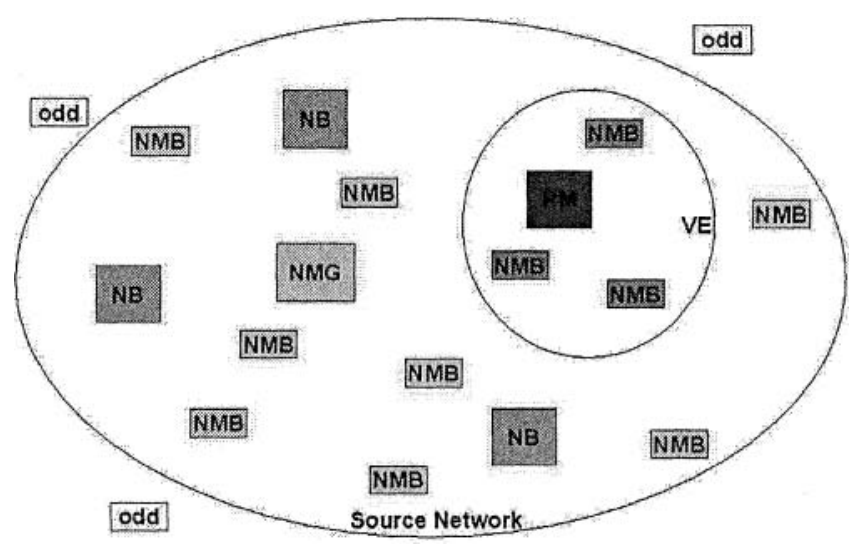

Figure 1 - Idea of a source network for electronic systems design

Main tasks related to each source network role are as follows.

1) Network Manager (NMG):

- defining service range offered by the network to potential customers

- maintenance of network knowledge (technical standards, standard network procedures related to the services offered)

- data maintenance about members core competences

- search for new network members and their registration

- evaluation of potential network members

- network members common activities financial control.

2) Network Broker (NB):

- search for customers and collecting external RFQ/orders

- marketing of network services and competences outside the network

- announcing possible projects inside the network (ad board, sending RFQ)

- organizing a competition for Project Managers concerning different projects

- passing details of the task and responsibility to the winning Project Managers

- participation in the customer - network contract negotiation together with PM.

3) Project Manager (PM): 
- preliminary detailed planning of a project (an electronic design task) determination of all sub-tasks and processes

- VE initiation (confirmation of final plan of the project)

- VE contract negotiation basing on the action plan confirmed during VE initiation

- VE/ design project coordination.

4) Network Member (NMB):

- search for customers and collecting external RFQ/orders - passing them to NB

- data maintenance about its core competences, tools, available IP

- possibility of search in NB ad board

- possibility of receiving RFQ and making the offers for NB (applying for the PM position) and PM (applying for the project participant position)

- cooperation with PM and others NMB within VE - project participation.

Not all tasks and functionalities mentioned above can be accomplished as a part of our IT system. Some of them must be supported by a human activity (e.g. a financial control or contractual negotiations). To make clearer the view of the network another model can be applied. This is a management-oriented process model that shows data flow and distribution of activities related to core business processes of the network. This model is depicted on Figures 2, 3, and 4. Here we concentrate on functionalities to be carried out by the IT system.

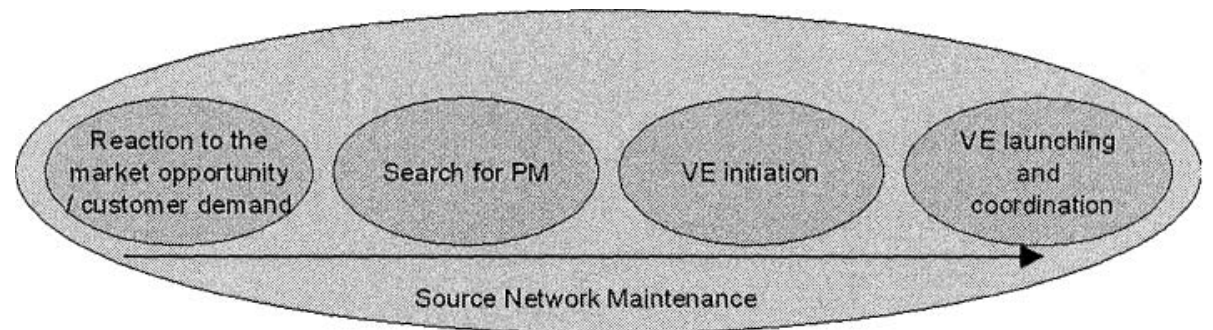

Figure 2 - Main functionalities (business processes) of the network.

Models illustrated above have a rather descriptive character. When the IT infrastructure of a source network is designed we have to apply more sophisticated models that cover in detail all small steps, exceptions, data entities, and possible scenarios. These models should be created by using a dedicated modeling language and tool. The choice of a proper modeling language depends highly on the technology provided. In our opinion the web services (WS) technology is the most suitable for source network implementation. 


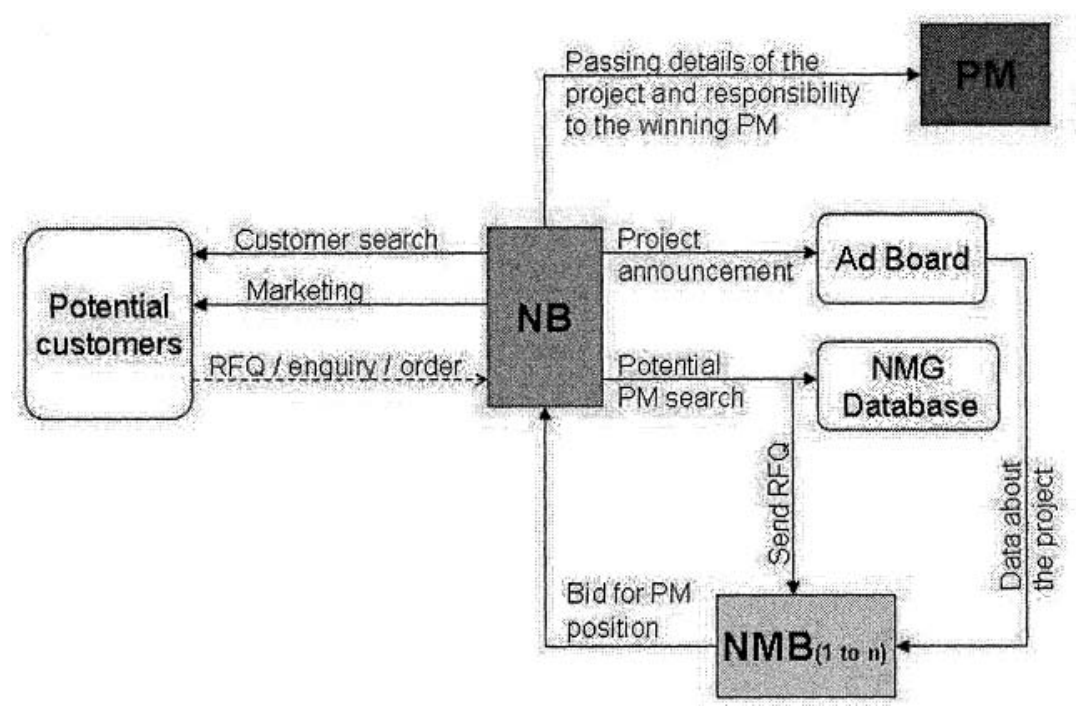

Figure 3 - Information flow and distribution of activities during PM search phase.

\section{VE CREATION - IMPLEMENTATION ISSUES}

The selection of the WS technology as a base technology for source network implementation is due to several factors. This technology provides the possibility for secure business processes execution and exposition in the Internet domain outside of firewalls. It gives a possibility for business processes publishing as services. Although the services can use internal data, they are separated from more stable company systems because they are located on WWW servers. WS are based on universally agreed specifications and standards (HTTP, XML, SOAP, WSDL), which do support their interoperability. Since WS are based on XML, they are proper for information exchange among heterogeneous systems, so the access to them is possible from any platform.

Management-oriented process modeling is a source for the IT system model which should be accomplished with use of a dedicated modeling language. There are many enterprise modeling languages (ATHENA, 2005) that could be used for a virtual distributed organization. If WS are to be applied, one can consider the following: UML (Unified Modeling Language), UEML (Unified Enterprise Modeling Language), UML for EAI (UML for Enterprise Application Integration), WSCDL (Web Services Choreography Description Language), WSCI (Web Service Choreography Interface), BPEL4WS (Business Process Execution Language for Web Services) shortly named BPEL. A proper modeling language can give the possibility for direct usage of the model during the implementation process. Thus the best choice seemed to be UML, WSCI, WSCDL, and BPEL. However the real value of the proposed languages can only be assessed during the implementation. It seems that our solution requires usage of a couple of them. 


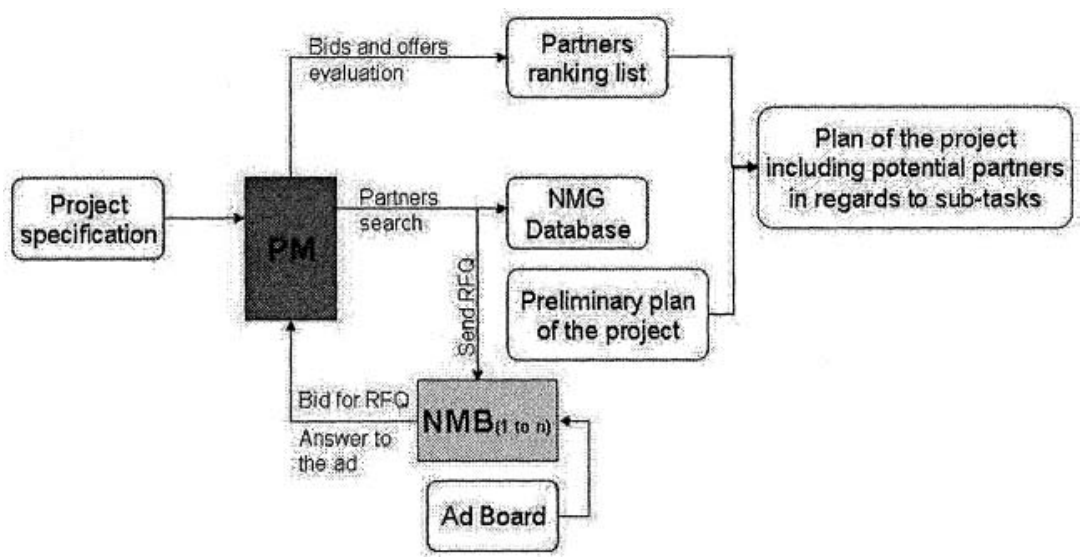

Figure 4. Information flow and distribution of activities during VE initiation phase.

An implementation endeavor has been focused on the VE initiation phase so far. This stage consists of the following steps (see Figure 4):

1) PM searches for partners within data stored on NMG servers (project requirements are taken into consideration).

2) PM sends RFQ to the several NMBs chosen (potential project participants).

3) NMBs answer RFQ sent by PM or answer to NB ad read on the ad board.

4) Offer evaluation by PM - building a ranking list of potential project participants for each design sub-task in the project (considering core competencies, available tools and IP catalogs, as well as trust and own past experiences).

5) PM creates preliminary plan of the project including all sub-tasks and potential partners (preliminary VE contract definition).

The VE initiation module that helps to complete these steps is a part of the whole IT system for the source network drafted above. The system realizes all necessary functionalities through flow of proper software applications. A part of these applications can be executed due to web services that are placed on WWW servers of different network members. Which services are located on the server depends on the role the company plays in the source network. In the following a list of applications and services needed for the VE initiation module is enumerated:

- WWW NMG server:

- Access to data about different NMBs - PM fills in a form of required competencies / tools / IP data and database search is performed

- Access to data about potential projects / NB ad board

- WWW PM server:

- VE potential partners list creation based on the service and data from NMG

- Sending RFQ to the potential partners from the list (taking into account required competencies, description of the task)

- Receiving and evaluation of the offers given by NMBs- building a ranking list of potential project participants for each design sub-task in the project 
- Based on the offers given by NMBs planning the projects (task flow, time schedule, responsible partners and their potential substitutes)

- WWW NMB server:

- Reading NB ad board

- Answering to RFQ from PM and to NB's ad (info about its own competencies and resources, evaluation of its own preparedness for the project participation, etc.).

As pointed out above, web services composition can be performed with aid of different languages. Each one has some advantages and disadvantages. We preferred to model the IT system with graphical UML. Then we can migrate to either BPEL or WSCI. This action can be already automatically made with proper tools like for instance: Emerging Technologies Toolkit version 1.1 (ETTK) released by IBM / Alphaworks, which takes process defined in the UML and generates the corresponding BPEL and WSDL files to implement that process (Mantell, 2003).

To model the complete functionality of a system more than one modeling language is necessary in order to organize WS execution. BPEL is appropriate for WS orchestration and WSCI is suitable for WS choreography (dos Santos, 2004). WS orchestration is a description of services behavior with applying workflow concepts. This description is interpreted and executed by an orchestration engine that is controlled by one of the services. Applying BPEL is useful when we have to coordinate complex processes that consist of many executable services. The choreography approach is less centralized. Each service only "knows" about its own interactions and behavior. There is no process that has a global control of the composition. Both discussed languages for WS composition description, depending on the functionality performed, should be adopted in the system. Currently the detailed IT model of the whole source network is under development. During this action the mentioned modeling languages will be investigated for their appropriateness for particular cases.

\section{SoC DESIGN INITIATION - A SCENARIO EXAMPLE}

In this section a scenario example of System-on-Chip (SoC) design initiation is presented. We assume that the source network received an enquiry concerning SoC design. The required system should be composed of a microprocessor part, memory, and $\mathrm{I} / \mathrm{O}$ interfaces. Detailed requirements are included in the specification attached to the enquiry sent by a customer. We also assume that PM has been established and that PM prepared a preliminary plan of "IP re-use" design project including design sub-tasks: IP component search and selection, design creation, simulation, synthesis, verification. The scenario shows a possible project initiation phase (Figure 5).

The preliminary plan of a design project is an input data for further actions. This plan defines the main sub-tasks (the required core competencies related to them), required IP components (that should be available - in our example these are: microprocessor, memory, I/O interface), and tools (e.g. software to perform certain design sub-tasks). The service "Partners search" (1) checks data records stored on NMG server about all NMBs and as a result gives addresses of all NMBs that have required factors marked as positive (answer: The best partners(2)). Then PM sends detailed RFQ to all NMBs indicated (3). An answer to RFQ service is a bid received 
from each interested NMB. The bids (4) are of similar form to the answer about the best partners (2) - these are a kind of forms that include evaluation of all important factors mentioned above. The evaluation is more precise this time - not only positive or negative but each factor is assessed by a number of points. Since the evaluation is made by NMB itself, it is called a subjective evaluation. The form of a bid can include additional fields like e.g. availability in a specified time period, price for sub-tasks to be completed by the particular NMB. The bids can be filled in automatically by the service located on the NMB server or with human assistance. The same forms in regards to all offering NMBs are filled in by PM according to its previous knowledge and experience with specific NMB. After summing the "objective" evaluation made by PM with "subjective" evaluations of NMB, PM receives ranking lists of potential partners that gives the possibility to create the final plan of the project with potential partners given for each sub-tasks. The next step will be the contract negotiation that is assumed to be accomplished without an IT system help.

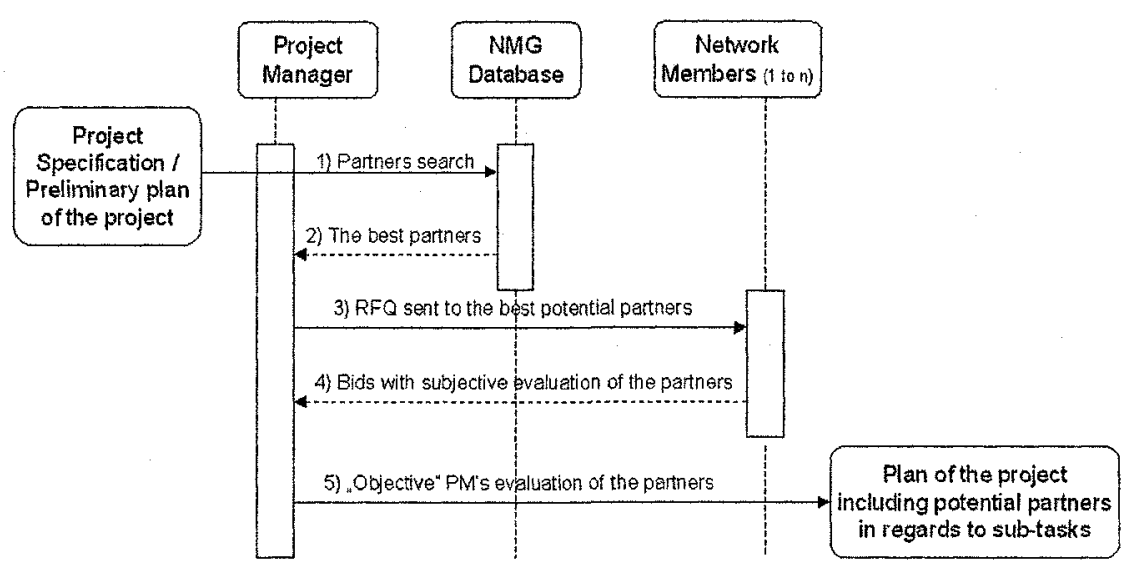

Figure 5 - An envisaged scenario of a project initiation

\section{CONCLUSIONS}

A contribution of the paper in relation to already published research results is mainly in the proposed model and methodology. Innovation is also in an application domain, namely in electronic systems design. The employed Web Services technology, although very popular nowadays, is still not mature enough, so dealing with it can bring new findings. Some of them have been envisaged in the paper.

The proposed model of the source network organizes the work of the whole network in such a way that the response to the customer's enquiry or market demand can be really fast. The model includes small number of key roles in the source network. The responsibilities are clearly shared. The main responsibility is taken by the PM that decides about project participants and a precise project plan. Some important activities, like negotiation or contracting need to be completed with a human assistance. 
The methodology includes only two network internal competitions - for PM establishment and for a proper design partners selection. The whole VE creation procedure is quite simple and many of its steps are accomplished promptly and automatically with the use of WS. The value of the presented solution when compared to the competing ones is its simplicity. The methodology of partner selection could be improved in future by applying a more sophisticated multi-criteria mathematical support for building potential partners ranking list.

We expect that the technologies applied during the current system development will lead to an easy communication within the heterogeneous source networks. Due to the similarity of both internal competitions some of web services can be likely used in both of them exchangeable.

The proposed source network concept has been influenced strongly by the application domain. A VO dedicated for design projects should have centralized management, hence the role of PM is so strong. Consequently the fact that PM has to plan and coordinate the whole project affects relatively simple model and methodology. An idea of conducting electronic systems design by VE created on the source network base is also an original one.

\section{ACKNOWLEDGMENTS}

This work has been realized in the Collaborative Engineering Group of the Institute of Electronics, Silesian University of Technology. It has been partially supported by the EU MAPPER project (FP6-2004-IST-NMP-2 No 016527).

\section{REFERENCES}

1. ATHENA project's public deliverable, WD A1.1.2 - State of the Art in Enterprise Modeling Techniques and Technologies to Support Enterprise Interoperability, 2005, www.athena-ip.org;

2. Camarinha Matos, L. M. - A platform to support production planning and management in a virtual enterprise - Proceedings of CAPE'97- IFIP/SME Int. Conference on Computer Applications in Production and Engineering (Chapman \& Hall), Detroit, USA, Nov 97;

3. Camarinha Matos, L. M.; Atsarmanesh, H.; Rabelo, R. J. - Infrastructure developments for agile virtual enterprises, International Journal on Computer Integrated Manufacturing, 2001;

4. Katzy, B.; Zhang, C.; Löh, H. - Reference Models for Virtual Organisations - in Virtual Organizations - Systems and Practices, Springer 2005, ISBN: 0-387-23755-0

5. Camarinha Matos, L. M.; Silveri, I; Afsarmanesh, H.; Oliveira, A. I. - Towards a Framework for Creation of Dynamic Virtual Organizations - in Collaborative Networks and their Breeding Environments, Springer 2005, ISBN: 0-387-28259-9

6. ECOLEAD public deliverable, D 21.1 - Characterization of Key Components, Features, and Operating Principles of the Virtual Breeding Environment, 2005, http//wwwecolead org;

7. Mantell, K. - From UML to BPEL - Model Driven Architecture in a Web services world, 2003, http://www-128. ibm.com/developerworks/webservices/library/ws-uml2bpel/index.htm!;

8. Rabelo, R. J.; Baldo, F.; Tramontin, R.; Pereira-Klen, Jr., A.; Klen, E. R. - Smart Configuration of Dynamic Virtul Enterprises, IFIP 18th World Computer Congress, Toulouse, France, 2004;

9. dos Santos, I. J. G.; Madeira, E. R. M. - VM-FLOW: Using Web Services Orchestration and Choreography to Implement a Policy-based Virtual Marketplace, IFIP 18th World Computer Congress, Toulouse, France, 2004;

10. Shields, B.; Molloy, O. - Dynamic Configuration of Collaboration in Networked Organisations, IFIP 18th World Computer Congress, Toulouse, France, 2004;

11. Witczyński, M.; Pawlak, A. - Virtual Organizations in the Electronic Sector - in Virtual Organizations - Systems and Practices, Springer 2005, ISBN: 0-387-23755-0 